\title{
Deep brain stimulation induces antiapoptotic and anti-inflammatory effects in epileptic rats
}

\author{
Beatriz O. Amorim ${ }^{1}$, Luciene Covolan ${ }^{1 *}$, Elenn Ferreira ${ }^{1}$, José Geraldo Brito ${ }^{1}$, Diego P. Nunes ${ }^{1}$, David G. de Morais ${ }^{1}$,
} José N. Nobrega ${ }^{2}$, Antonio M. Rodrigues ${ }^{3}$, Antonio Carlos G. deAlmeida ${ }^{3}$ and Clement Hamani ${ }^{2,4}$

\begin{abstract}
Background: Status epilepticus (SE) is a severe condition that may lead to hippocampal cell loss and epileptogenesis. Some of the mechanisms associated with SE-induced cell death are excitotoxicity, neuroinflammation, and apoptosis.

Objective: The objective of the present study is to test the hypothesis that DBS has anti-inflammatory and antiapoptotic effects when applied during SE.
\end{abstract}

Methods: Rats undergoing pilocarpine-induced SE were treated with anterior thalamic nucleus (AN) deep brain stimulation (DBS). Inflammatory changes and caspase 3 activity were measured within 1 week of treatment.

Results: In pilocarpine-treated rats, DBS countered the significant increase in hippocampal caspase 3 activity and interleukin-6 (IL-6) levels that follows SE but had no effect on tumor necrosis factor a (TNFa).

Conclusions: DBS has anti-inflammatory and antiapoptotic effects when given to animals undergoing status.

Keywords: Anterior thalamic nucleus, Thalamus, Seizures, Deep brain stimulation, Epilepsy, Apoptosis,

Neuroprotection, Caspase

Status epilepticus (SE) is a condition associated with continuous seizure activity that often leads to excitotoxicity and cell death [1]. Deep brain stimulation (DBS) of the anterior thalamic nucleus (AN), an approved treatment for medically refractory partial epilepsy [2], has been shown to reduce seizure rate and increase the latency for the development of SE in different rodent models [3-6]. To date, whether stimulation is protective against SE-induced excitotoxicity is largely unknown.

In Parkinson's disease, subthalamic nucleus DBS has been proposed to induce neuroprotective effects by reducing the glutamatergic drive to the substantia nigra [7]. In a parallel scenario, AN stimulation inhibits the spontaneous activity of local neuronal populations and reduces the firing rate of dentate gyrus cells [8]. Following this line of reasoning, we hypothesize that a decreased drive to the

\footnotetext{
* Correspondence: lucovolan@gmail.com

'Disciplina de Neurofisiologia, Universidade Federal de São Paulo, Rua Botucatu, 8625 andar, 04023-062 São Paulo, Brazil

Full list of author information is available at the end of the article
}

hippocampus following AN DBS could have neuroprotective effects.

In preclinical models [9] and in the clinic [10, 11], neuromodulation treatments that induce antiepileptic effects, such as vagus nerve stimulation (VNS), have been shown to reduce plasmatic levels of cytokines.

In the present study, we test the hypothesis that AN DBS reduces hippocampal apoptosis and neuroinflammation in rats undergoing pilocarpine (Pilo)-induced SE.

\section{Methods}

Ethics, consent, and permissions

Experiments were approved by the Animal Care committee of the Universidade Federal de São Paulo (1482/11).

\section{Pilocarpine administration and AN stimulation}

Male Wistar rats $(\sim 250 \mathrm{~g})$ were anesthetized with ketamine/xylazine (100/7.5 $\mathrm{mg} / \mathrm{kg}$ i.p.) and had insulated stainless steel electrodes (cathodes; 250- $\mu$ m diameter; 0.5 -mm exposed surface) bilaterally implanted into the AN (anteroposterior -1.5 , lateral \pm 1.5 , depth 5.2) [12]. A 
screw implanted over the right somatosensory cortex was used as the anode. Control animals had holes drilled into the skull but were not implanted with electrodes. Animals undergoing electroencephalography (EEG) recordings were implanted with bipolar cortical electrodes (Plastics One; $3 \mathrm{~mm}$ posterior, $4 \mathrm{~mm}$ lateral, and $2 \mathrm{~mm}$ ventral to the bregma) [12]. One week later, animals received $N$-methyl-scopolamine $(1 \mathrm{mg} / \mathrm{kg}$ s.c. Sigma, St Louis, MO) followed, $30 \mathrm{~min}$ later, by pilocarpine (320 mg/kg, i.p., Vegeflora, Brazil). SE was characterized by the presence of uninterrupted behavioral seizures [24]. As pilocarpine-induced seizures often last a few seconds, DBS was commenced 1 minute after SE onset. Stimulation settings were in the range of those used in our previous studies: $130 \mathrm{~Hz}, 90 \mu \mathrm{s}$, and $400 \mu \mathrm{A}$ (St Jude MTS, Plano, TX) [3].

Ninety minutes after SE, the animals received thionembutal $(30 \mathrm{mg} / \mathrm{kg})$ to attenuate behavioral status and reduce mortality rate. As animals began to recover $6 \mathrm{~h}$ later, DBS was delivered continuously during the first $6 \mathrm{~h}$ of status.

EEG was recorded with a BNT-36 system (Lynx, Brazil) using the ENSA software (ENSA, Brazil) for $24 \mathrm{~h}$ from the moment Pilo was injected. Signals were amplified, band pass filtered $(0.1-30 \mathrm{~Hz})$, and digitized (200 samples/s). Complex Gaussian's wavelet transform analysis was used to investigate the signals in the frequency domain. Placement of DBS electrodes was confirmed in cresylviolet-stained sections and was similar to that described in our previous reports [13].

\section{Caspase 3 and cytokine measurements}

After removal from the skull, the brains were split in half, and the hippocampus of each hemisphere was dissected. The left hippocampus was used for the study of caspase activity. The right hippocampus was used to measure cytokines.

The hippocampus of each animal was incubated with a homogenization buffer and mechanically homogenized, as previously described [14]. Samples were centrifuged for $40 \mathrm{~min}$, and the total protein content in the supernatant determined using the Bio-Rad Protein Assay, according to the manufacturer's specification (Bio-Rad Labs, Germany). Measurement of caspase 3 activity was obtained using the caspase 3 fluorimetric assay kit (CASP3F, Sigma, USA). Triplicates of each sample (all containing $100 \mathrm{mg}$ of protein) were analyzed. All received the substrate but only one the inhibitor. Activity was measured continuously over $5 \mathrm{~h}$ on a FlexStation 3 Spectrofluorimeter (Molecular Probes, USA), using $\lambda \mathrm{ex}=360 \mathrm{~nm}$ and $\lambda \mathrm{em}=$ $465 \mathrm{~nm}$. Values obtained from samples containing the inhibitor were subtracted from those recorded from the other samples, and the arithmetic average was calculated. After calibration for AMC, results were expressed as $\mathrm{nMol}$ AMC.
For cytokine detection, the right hippocampus was homogenized in $0.01 \mathrm{M}$ Tris hydrochloride ( $\mathrm{pH}$ 7.6) containing $5.8 \%$ sodium chloride, $10 \%$ glycerol, $1 \%$ Nonidet P40 (NP-40), $0.4 \%$ of ethylenediamine tetraacetic acid (EDTA), and protease inhibitors. Samples were sonicated and stored at $-80{ }^{\circ} \mathrm{C}$. Subsequently, samples were centrifuged for $5 \mathrm{~min}$. at $10,000 \times g$ at $4{ }^{\circ} \mathrm{C}$, and concentrations determined with a Millipore multiplex Rat Cytokine Kit (RECYTMAG-65K-03) on the Luminex ${ }^{\circ} \mathrm{xMAP}^{\circ}$ platform (xPonent/Analyst Software version 4.2). Longitudinal controls were used to assess inter-assay variability. Results are expressed in $\mathrm{pg} / \mathrm{mg}$.

\section{Statistical analysis}

Two-way ANOVA (DBS and Pilo as main factors; Tukey post hoc) was used to compare neurochemical data. Electrophysiological results were analyzed with Wilcoxon signed-rank test. Values in the text represent mean \pm SEM.

\section{Results}

\section{Apoptosis and neuroinflammatory changes}

Hippocampal caspase 3 activity was studied 7 days following SE, a time frame during which apoptosis reaches maximal levels $[15,16]$. At this time point, we found significant Pilo $\left(F_{(1,16)}=17.17 ; P=0.0008\right)$ and DBS effects $\left(F_{(1,16)}=10.34 ; P=0.005\right)$. As can be seen in Fig. 1 , caspase 3 activity was increased in pilocarpine-treated rats $(n=5)$ as compared to saline-injected controls $(n=5 ; P=0.009)$. The administration of DBS significantly reduced such activity $(n=5)$, bringing it to a level that was similar to that of non-epileptic controls $(n=5 ; P=0.02$ vs Pilo). In contrast, no significant Pilo $\left(F_{(1,16)}=0.01 ; P=0.95\right)$ or DBS effects $\left(F_{(1,16)}=1.97 ; P=0.18\right)$ were recorded when caspase 3 activity was measured 24 h following status epilepticus (Additional file 1: Figure S1; $n=5$ animals/group).

Markers of inflammatory activity were studied 1 day following status, when post-SE changes are at high levels $[17,18]$. Hippocampal pro-inflammatory IL-6 was influenced by both Pilo $\left(\mathrm{F}_{(1,14)}=9.85 ; P=0.007\right)$ and DBS $\left(\mathrm{F}_{(1,14)}=9.23 ; P=0.008\right)$ with interaction between both factors $\left(\mathrm{F}_{(1,14)}=4.53 ; P=0.05\right)$. Overall, levels of this interleukin were slightly reduced in AN DBS control animals, a response that was further evidenced after status $(P=0.002$ vs Pilo) (Fig. 1). Although TNF levels were in the lower limit of the detection of the fluorimetric assay, these were found to be influenced by Pilo $\left(F_{(1,14)}=22.60\right.$; $P=0.0003$ ) but not DBS.

To investigate whether the protective effects of DBS were due to a decrease in SE severity, EEG recordings were obtained before and during status ( $n=5$ per group). Though tracings looked similar between groups, spectral analysis revealed that animals receiving DBS had a significant decrease in alpha and beta band peaks (Additional 

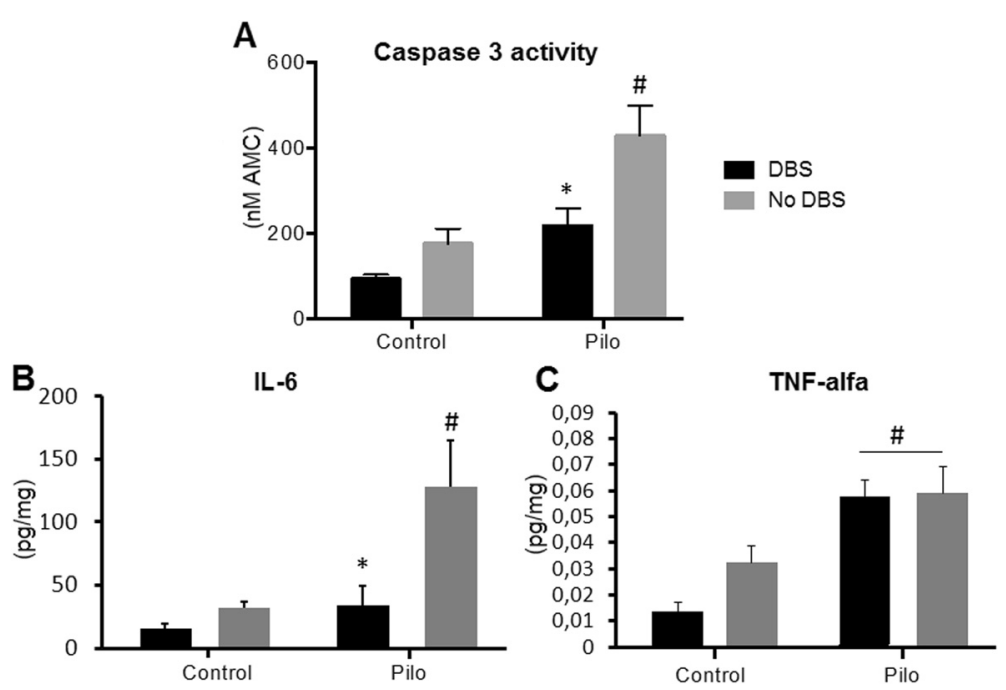

Fig. 1 DBS, apoptosis, and neuroinflammation. (a) Hippocampal caspase 3 activity was increased in pilocarpine-treated rats undergoing SE ( $P=0.009$; vs saline controls), an effect that was significantly reversed in the DBS-treated Pilo group ( $P=0.02$; vs Pilo). Similarly (b), hippocampal levels of the pro-inflammatory IL- 6 were significantly increased after SE ( $P=0.006$; vs saline-injected controls), an effect that was countered by the administration of AN DBS ( $P=0.02$; vs Pilo). In contrast, SE-induced increases in TNFa ( $P=0.0003$ vs saline-injected controls) were not influenced by DBS (c). \# indicates differences from control, *indicates differences from Pilo

file 2: Figure S2). This suggests that DBS may potentially decrease SE severity.

\section{Discussion}

It is well established that seizures and SE can activate intrinsic and extrinsic apoptotic pathways leading to neuronal death. As a common final step, caspase 3 activation invariably leads to an irreversible apoptotic process. In rodents, caspase 3 is active $24-72 \mathrm{~h}$ following status but maximally expressed 7 days later [19]. Our results suggest that animals given DBS during status had a significant decrease in hippocampal caspase 3 activity, as measured by a commercial protein assay. While this method was reliable and showed low variability across animals, it did not allow us to determine in which hippocampal subregions apoptosis was occurring. In a preliminary immunohistochemistry experiment (unpublished data), we found that animals undergoing SE with or without DBS had caspase-3expressing cells in the dentate gyrus, CA1, and CA3 subfields. This technique, however, has only shown sparsely stained cells and a great variability across rats. Whether the effects of DBS are related to a decrease in apoptotic processes or a lower number of hippocampal cells undergoing cell death remains to be elucidated.

Another technical aspect that needs to be discussed is the choice of a control group without electrodes implanted. This was based on our previous studies showing that electrode insertion did not influence the latency for developing SE or the frequency of seizures in pilocarpine-treated rats $[3,20]$. Placement of electrodes in the brain often causes a mild local inflammatory response that tends to subside over time. Though it is possible that this might have occurred in the AN, samples in our study were collected at a distance from the target (i.e., in the hippocampus and not in the AN). In addition, an inflammatory response should have theoretically increased pro-inflammatory cytokines. In our study, DBS-treated animals had the opposite effect.

Most cells in the AN are immunocytochemically positive for glutamate and aspartate [21]. Connections between the AN and hippocampus are both direct (e.g., via subiculum and CA1) and indirect (i.e., via anterior cingulum and entorhinal cortex) [22, 23]. In our previous work, AN DBS was shown to induce a strong depolarization block of local neuronal populations and reduce the firing in hippocampal dentate gyrus cells [24]. Bearing this in mind, it is possible that reduced activity within the AN complex and DG following DBS might have decreased glutamate-induced excitotoxicity, reducing hippocampal caspase activity and inflammatory responses. This, however, still needs to be demonstrated.

Another possibility to explain potential neurochemical differences between animals that did or did not receive DBS is that stimulation might have influenced SE severity. Though EEG tracings looked similar between groups, a more detailed spectral analysis revealed that the rats given DBS had a decrease in alpha and beta power. This may represent a milder form of status epilepticus, as the withdrawal of anticonvulsant medications may enhance beta rhythms during continuous seizures [25].

One limitation of the current study is that we cannot infer a direct association between reduced excitotoxicity, anti- 
inflammatory, and antiapoptotic effects of DBS. Similarly, we are unable to explain why DBS has only influenced certain pro-inflammatory cytokines (i.e., IL-6 but not TNF $\alpha$ ).

\section{Conclusion}

As excitotoxicity and inflammatory responses are early occurring events following SE, we postulate that the reduced levels of apoptosis observed after DBS may be due, at least in part, to its anti-inflammatory effects. That said, our results do not allow one to establish a causal relationship between a DBS-induced reduction in cytokines and apoptosis, an aspect that needs to be investigated in the future.

\section{Additional files}

Additional file 1: Figure S1. Apoptosis $24 \mathrm{~h}$ after pilocarpine-induced status epilepticus. No significant differences were found in hippocampal caspase 3 activity when animals who developed pilocarpine-induced SE with or without DBS were compared to controls. (TIFF $94 \mathrm{~kb}$ )

Additional file 2: Figure S2. EEG activity recorded before and during SE in animals that did and did not receive DBS. (A) Traces of a non-stimulated animal before (left) and during (right) SE. Spectral arrays after wavelet transform of corresponding EEG traces show activity in the $a$ and $\beta$ bands during SE. (B) Traces of a DBS-treated animal before (left) and during (right) SE. Spectral arrays after wavelet transform of the corresponding EEG traces show that activity during SE in the $a$ and $\beta$ bands are reduced during AN DBS. (C) Box plot showing the mean power spectrum of different frequency bands pre-SE in animals that did not (yellow bars) or did receive AN DBS (blue bars). As stimulation was not turned on at that point, Wilcoxon signed-rank test showed no significant difference between groups $(P>0.05$, $n=5$ ). (D) Box plot showing the mean power spectrum of different frequency bands during SE without (yellow bars) and with AN DBS (blue bars). Wilcoxon signed-rank test showed significant differences between groups in the $a$ and $\beta$ bands ( $P<0.05, n=5$ animals/group). (TIFF $2135 \mathrm{~kb}$ )

\section{Competing interests}

$\mathrm{CH}$ is a consultant for St Jude Medical. The other authors have no competing interests.

\section{Authors' contributions}

Surgical procedures to implant electrodes, status induction, caspase 3 , and cytokine assays were carried out by BOA, EF, DPN, and DGM. BOA drafted the manuscript. AMR, JGB, and ACGA carried out the quantitative analysis of the EEG. JNN participated in the design of the study and performed the statistical analysis. CH and LC conceived of the study and participated in its design and coordination and helped to draft the manuscript. All authors read and approved the final manuscript.

\section{Acknowledgements}

The authors acknowledge FAPESP (2011/50680-2; 2012/50950-2; 2012/10764-5) for funding this study.

\section{Disclosure}

Support for this work was provided by FAPESP (Grant numbers: 2011/50680-2; 12/50950-2; 12/10764-5).

\section{Author details}

'Disciplina de Neurofisiologia, Universidade Federal de São Paulo, Rua Botucatu, 8625 andar, 04023-062 São Paulo, Brazil. 'Behavioural Neurobiology Laboratory, Centre for Addiction and Mental Health, Toronto, Canada. ${ }^{3}$ Departamento de Engenharia de Biossistemas, Universidade Federal de São João del-Rei, São João del-Rei, MG 36301-160, Brazil. " Division of Neurosurgery, Toronto Western Hospital, University of Toronto, Toronto, Canada.
Received: 13 December 2014 Accepted: 20 August 2015

Published online: 04 September 2015

\section{References}

1. Covolan L, Mello LE. Assessment of the progressive nature of cell damage in the pilocarpine model of epilepsy. Braz J Med Biol Res. 2006;39:915-24.

2. Fisher R, Salanova V, Witt T, Worth R, Henry T, Gross R, et al. Electrical stimulation of the anterior nucleus of thalamus for treatment of refractory epilepsy. Epilepsia. 2010;51:899-908.

3. Covolan L, de Almeida AC, Amorim B, Cavarsan C, Miranda MF, Aarao MC, et al. Effects of anterior thalamic nucleus deep brain stimulation in chronic epileptic rats. PLoS One. 2014;9:e97618.

4. Mirski MA, Rossell LA, Terry JB, Fisher RS. Anticonvulsant effect of anterior thalamic high frequency electrical stimulation in the rat. Epilepsy Res. 1997;28:89-100.

5. Takebayashi S, Hashizume K, Tanaka T, Hodozuka A. Anti-convulsant effect of electrical stimulation and lesioning of the anterior thalamic nucleus on kainic acid-induced focal limbic seizure in rats. Epilepsy Res. 2007;74:163-70.

6. Hamani C, Ewerton F, Bonilha S, Ballester G, Mello L, Lozano A. Bilatera anterior thalamic nucleus lesions and high-frequency stimulation are protective against pilocarpine-induced seizures and status epilepticus. Neurosurgery. 2004;54:191-5.

7. Rodriguez M, Obeso J, Olanow C. Subthalamic nucleus-mediated excitotoxicity in Parkinson's disease: a target for neuroprotection. Ann Neurol. 1998;44:S175-88.

8. Hamani C, Dubiela F, Soares J, Shin D, Bittencourt S, Covolan L, et al. Anterior thalamus deep brain stimulation at high current impairs memory in rats. Exp Neurol. 2010;225:154-62.

9. Borovikova LV, Ivanova S, Zhang M, Yang H, Botchkina GI, Watkins LR, et al. Vagus nerve stimulation attenuates the systemic inflammatory response to endotoxin. Nature. 2000;405:458-62.

10. Aalbers MW, Klinkenberg S, Rijkers K, Verschuure P, Kessels A, Aldenkamp A, et al. The effects of vagus nerve stimulation on pro- and anti-inflammatory cytokines in children with refractory epilepsy: an exploratory study. Neuroimmunomodulation. 2012;19:352-8.

11. Majoie HJ, Rijkers K, Berfelo MW, Hulsman JA, Myint A, Schwarz M, et al. Vagus nerve stimulation in refractory epilepsy: effects on pro- and anti-inflammatory cytokines in peripheral blood. Neuroimmunomodulation. 2011;18:52-6.

12. Paxinos $\mathrm{G}$, Watson $\mathrm{C}$. The rat brain stereotaxic coordinates. 2nd ed. London: Academic; 2005

13. Bittencourt S, Dubiela F, Queiroz C, Covolan L, Andrade D, Lozano A, et al. Microinjection of GABAergic agents into the anterior nucleus of the thalamus modulates pilocarpine-induced seizures and status epilepticus. Seizure. 2010;19:242-6.

14. Malheiros J, Persike D, Castro L, Sanches T, Andrade L, Tannús A, et al. Reduced hippocampal manganese-enhanced MRI (MEMRI) signal during pilocarpine-induced status epilepticus: edema or apoptosis? Epilepsy Res. 2014:108:644-52.

15. Weise J, Engelhorn T, Dorfler A, Aker S, Bahr M, Hufnagel A. Expression time course and spatial distribution of activated caspase-3 after experimental status epilepticus: contribution of delayed neuronal cell death to seizure-induced neuronal injury. Neurobiol Dis. 2005;18:582-90.

16. Narkilahti S, Pirttila TJ, Lukasiuk K, Tuunanen J, Pitkanen A. Expression and activation of caspase 3 following status epilepticus in the rat. Eur $J$ Neurosci. 2003:18:1486-96.

17. Gouveia TL, Scorza FA, Silva MJ, Bandeira Tde A, Perosa SR, Arganaraz GA, et al. Lovastatin decreases the synthesis of inflammatory mediators in the hippocampus and blocks the hyperthermia of rats submitted to long-lasting status epilepticus. Epilepsy Behav. 2011;20:1-5.

18. De Simoni MG, Perego C, Ravizza T, Moneta D, Conti M, Marchesi F, et al. Inflammatory cytokines and related genes are induced in the rat hippocampus by limbic status epilepticus. Eur J Neurosci. 2000;12:2623-33.

19. Lopez-Meraz M-L, Niquet J, Wasterlain C. Distinct caspase pathways mediate necrosis and apoptosis in subpopulations of hippocampal neurons after status epilepticus. Epilepsia. 2010;51:50-60

20. Hamani C, Hodaie M, Chiang J, del Campo M, Andrade DM, Sherman D, et al. Deep brain stimulation of the anterior nucleus of the thalamus: effects of electrical stimulation on pilocarpine-induced seizures and status epilepticus. Epilepsy Res. 2008;78:117-23.

21. Gonzalo-Ruiz A, Sanz JM, Lieberman AR. Immunohistochemical studies of localization and co-localization of glutamate, aspartate and GABA in the 
anterior thalamic nuclei, retrosplenial granular cortex, thalamic reticular nucleus and mammillary nuclei of the rat. J Chem Neuroanat. 1996;12:77-84.

22. Shibata H. Topographic organization of subcortical projections to the anterior thalamic nuclei in the rat. J Comp Neurol. 1992;323:117-27.

23. Shibata $\mathrm{H}$. Direct projections from the anterior thalamic nuclei to the retrohippocampal region in the rat. J Comp Neurol. 1993;337:431-45.

24. Malheiros JM, Polli RS, Paiva FF, Longo BM, Mello LE, Silva AC, et al.

Manganese-enhanced magnetic resonance imaging detects mossy fiber sprouting in the pilocarpine model of epilepsy. Epilepsia. 2012;53(7):1225-32.

25. Bonati LH, Naegelin Y, Wieser HG, Fuhr P, Ruegg S. Beta activity in status epilepticus. Epilepsia. 2006;47:207-10.

\section{Submit your next manuscript to BioMed Central and take full advantage of:}

- Convenient online submission

- Thorough peer review

- No space constraints or color figure charges

- Immediate publication on acceptance

- Inclusion in PubMed, CAS, Scopus and Google Scholar

- Research which is freely available for redistribution 